\title{
EFL Female Students' Perceptions towards Cheating in Distance Learning Programmes
}

\author{
Alaa Mamoun Saleh ${ }^{1} \&$ Zilal Meccawy ${ }^{1}$ \\ ${ }^{1}$ English Language Institute (ELI), King Abdulaziz University (KAU), Jeddah, Kingdom of Saudi Arabia, P.O. \\ Box 42801, Zip Code 21551. https://orcid.org/0000-0003-4080-7565 and https://orcid.org/0000-0002-4052-3469 \\ Correspondence: Zilal Meccawy, English Language Institute, King Abdulaziz University, Jeddah, Kingdom of \\ Saudi Arabia, P.O. Box 42801, Zip Code 21551. E-mail: zmeccawy@kau.edu.sa
}

Received: November 10, 2020

Accepted: December 2, 2020

Online Published: December 10, 2020

doi: $10.5539 /$ elt.v14n1p29

URL: https://doi.org/10.5539/elt.v14n1p29

\begin{abstract}
Distance education is becoming more in demand at universities all around the world in general and in the Kingdom of Saudi Arabia (KSA) in particular, than ever before. This study aimed at highlighting the students' perceptions of cheating on a distance learning programme at King Abdulaziz University (KAU). The study will further explore the ways they use to cheat, causes for cheating, and some solutions to minimize cheating. This study was conducted at the end of the second semester in 2019. Data was collected from 57 female distance learning students who graduated from the English Language Department at KAU. A mixed-methods research design was adopted in this study via a custom designed, fifteen closed-ended and one open-ended item questionnaire. The quantitative section was analysed by frequency and percentages and the open-ended questions were analysed thematically. The results indicated that the majority of female students cheated by helping each other, obtaining the correct answers from other students or sending the correct responses to all their classmates. Another way which some students admitted they employed was using electronic websites to copy and paste the answers onto the test's screen. The study further concluded that reasons for cheating in distance learning programs were due to technical problems, frequent absence of virtual classes, and students wanting grades, not necessarily knowledge. Recommendations for possible solutions to eliminate cheating, participants themselves recommended increasing students' awareness of cheating policy and finding solutions to common technological issues.
\end{abstract}

Keywords: cheating, distance learning, EFL, Saudi Arabia, student perceptions, virtual classes, academic dishonesty

\section{Introduction}

As a result of all developments and inventions around the world, formal education is becoming one of the most important aspects of life. Many types of education are being offered by various universities, one of which is e-learning or distance learning. Thus, in this modern world in which the Internet and the virtual world play a substantial role; distance learning begins to play a major role in the field of education (Almazova, Khalyapina, \& Popova, 2016). Distance learning programs enable students to foster self-direction and self-independent modes. Moreover, teachers are able to encourage shy students to participate and discuss without any fear from their classmates as in traditional classes (Ibrahim, Silong, \& Samah, 2002). Furthermore, distance learning has provided many opportunities for part-time students and working staff to complete their studies. Moreover, distance learning saves more money than regular learning (Sadeghi, 2019). However, several negative issues emerge as a result of e-learning. These include depriving the students of live interactions with their teachers and other classmates, the shorter time given to virtual classes, and ample opportunities to cheat (Harashchenko et al., 2019). Subsequently, understanding the students' attitude of cheating in an online learning environment is significant to the teachers and students. In KSA, KAU has established the Deanship of E-learning and Distance Education in 2005 (Alhareth \& Mcbride, 2014). Since then, many students have studied in online learning programs and gained knowledge and degrees as it was a significant movement in the educational field.

\subsection{Purpose of the Study}

Despite the fact that there are many studies about academic dishonesty, little research has been conducted on cheating in distance-learning programmes at universities in Saudi Arabia. This study aims to identify the 
perceptions of distance learning students in terms of how they cheat, why they cheat in online courses and to offer some possible solutions to this problem.

\subsection{Research Questions}

This research aims to answer the following questions:

1. What are the distance learning students' perceptions about the ways they cheat at online at KAU? What are their reasons for cheating?

2. What are the participants' perceptions towards the most practical solutions to prevent cheating in distance-learning at KAU?

\subsection{Background of the Study}

King Abdulaziz University was established in 1967 and it has become a major university in the Middle East, due to its various educational programs and high student numbers. Its educational system has been developed over the years, and in addition to traditional classrooms, the university offers other programs such as distance learning and external learning. The university accepted its first class of distance learning students in the Fall of 2007

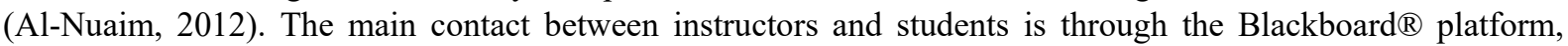
which the university grants access for students to use through their phones or laptops. There are no traditional classrooms, all the lectures are conducted by virtual classrooms via Blackboard ${ }^{\circledR}$, and all assignments, forums, and tests are sent online, except for the final exam, which is in taken at the university. On account of distance learning' advantages, the education equipment for new students is reduced and for the distance-learners who are worker or parents, online-learning gives them flexibility with virtual lectures. Additionally, online courses' materials could help teachers to develop teaching methods and present the contents of the lessons more creatively (Malik, Al Shaer, \& Arora, 2019). That helps to engage the students and make learning more effective. A substantial advantage of such a programme is that learners with disabilities or special educational needs can complete their education without any difficulty (Masaryk, Sokolová, \& Túnyiová, 2018). On the other hand, distance learning programs at KAU face many obstacles, which can be divided into four main categories: technical issues, financial issues, societal issues, and administrative issues (Alhareth \& Mcbride, 2014). Regarding the difficulties that many students encounter, three main barriers are the most significant: 1) lack of strategies', 2) few opportunities for practicing and interaction with others, and 3) time management (Hurd, 2000) with the most marked disadvantage of cheating to gain correct information (Alghamdi, Rajab, \& Rashid, 2016).

\subsection{Limitations of the Study}

This research had some limitations, one of which was the small sample size. Moreover, all the participants were female students due to the gender segregation rules in the Saudi Education system where the researchers had limited access to male participants. Additionally, there was no specific procedure to observe how students might commit online cheating.

\section{Literature Review}

\subsection{Definition of Distance Learning}

It is necessary here to define what is meant by distance learning. It is the learning which happens at different places where learners and instructors are using the Internet. Although the learner is not physically in class, he or she corresponds to the course and interacts through a mediator program (Moore, Dickson-Deane, \& Galyen, 2011). The instructor uses technological tools that are web-based most of the time (Nichols, 2003).

\subsection{Definition of Cheating}

Raines et al. (2011) define cheating as breaking the rules, dishonesty and not doing the work ethically. In their study, $66 \%$ of the participants referred to cheating as doing something which is opposed to university policies and the professors' guidelines. In the current online context, this includes obtaining inappropriate assistance either from friends or the Internet. So, any way in which the student is gaining information and the professor has not authorized is considered cheating. In academic cheating, there are some goals that convince students to go-ahead and cheat; for example, achieving a higher grade without studying, completing a course successfully and getting a better job in the future (Owen, 2016).

\subsection{Methods of Cheating in Distance Learning}

Many researchers determined various ways students used to cheat in online courses. Interestingly, females were more likely to get answers from others during a test or quiz in online courses (Watson \& Sottile, 2010). In their study, data were collected through a survey of 635 students' responses and students mentioned two main ways to 
cheat. The first was obtaining other students' work without their permission and the second was taking passages from an article or a book directly without any citation.

Other common ways of online cheating are: identity impersonation, students' collaborating dishonestly and sharing assignment files with each other (Ravasco, 2012). Fabricating or falsifying a reference is also a common way that most of Saudi participants used (Razek, 2014). Copying from the Internet, especially during the online exam/test, is another widespread method that students frequently use. Golden and Kohlbeck (2020) stated that using verbatim questions in online tests helps the students in copying the items and getting the right answers from the Internet, while paraphrasing questions represents a challenge for students who wish to cheat.

\subsection{Reasons for Cheating in Distance Learning}

There are many reasons that cause online cheating, which are committed by students. For example, lack of responsibility, laziness, lack of respect for academic rules and being apathetic are the most important internal reasons. Also, students whose self-efficacy is lost tend to cheat more than confident learners (Baran \& Jonason, 2020). Additionally, students who usually do not attend lectures, misunderstand content, and do not review their lessons beforehand (Diego, 2017). Their absence from lessons and lack of study time are obvious causes of cheating (Hosny \& Fatima, 2014). Another reason is the pressure from parents, where the students may feel ashamed to get low grades and thus tend to cheat. Diego (2017) emphasised that learners' cheating aptitude is rooted in the elementary years of school and most students consider cheating as a social and connecting behaviour, which means they share the answers even if they know it is not honest. Technical problems with the

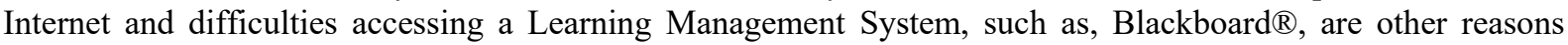
which cause distance learning students to cheat.

\subsection{Solutions to Cheating in Distance Learning}

Solving the problem of cheating in distance learning is essential to implement the programmes effectively. Rowe (2004) suggested many solutions to prevent cheating in online courses, which include signing a policy statement at the beginning of each course (suggested by Michael and Williams (2013); and King, Guyette Jr, and Piotrowski (2009)) and providing details about ethics, procedures and instructions. Teachers should also understand what students face in distance-learning as well as having a designated security manager for the site, and closing all ports: critically ports 21 (file-transfer), 23 (remote-login), 25 (mail), and 443 (secure Internet connections) (Rowe, 2004). Teachers can also start the semester with a presentation about academic integrity, which could help students understand the risks of being cheaters.

Michael and Williams (2013) added other solutions, such as decreasing the number of Multiple Choice Questions (MCQs) and increasing essay question forms, short answers, exam software showing one question at a time, and teachers being familiar with students' level to determine who really wrote the assignments. In the Saudi educational context, Razek (2014) identified 13 student participants' perceptions about cheating and concluded that Saudi students tend to cheat because they feel that an inevitable failure will materialise if they do not receive any help from their colleagues, adding to that the results showed the importance of grades more than learning. The researcher recommended promoting ethical awareness and concentrating on educational knowledge rather than the GPA.

In a local research, Hosny and Fatima (2014) conducted a study at King Saud University, Riyadh, Saudi Arabia trying to understand the attitude of female students toward cheating and plagiarism. The study involved 148 participants who completed a questionnaire, and the results showed that cheating is a usual attitude among the students and the most common way is to pay someone else to do the assessments. The students blamed the modern and fast-paced life as they do not have time for studying. However, few studies have investigated dishonesty in distance learning. This study aims to contribute to this growing area of research by exploring distance learning students' perceptions at King Abdulaziz University toward cheating, especially the ways students use to cheat, causes leading to cheating, and some solutions to prevent this problem.

\section{Methodology}

As a methodological basis for this research, a mix methods research design was adopted where quantitative and qualitative primary data were collected in order to explore cheating in a distance learning programme and identify some solutions for this. This was done because quantitative research is searching for quantities in a matter and to establish research numerically (Sukamolson, 2007), whilst, qualitative studies address the social aspect of research (Choy, 2014). 


\subsection{Participants}

The participants of the research consisted of distance learning students in Higher Education (HE) in Jeddah, Saudi Arabia. The sample of this study was the distance learning students at the English Language Department at KAU. The study was conducted at the end of the second semester of 2018/2019. The participants were selected purposefully according to the aim of the study. This meant that a convenience sampling technique was used. The participants were 57 female university distance learning students, who have studied at least two online courses. All respondents' identities were kept anonymous in accordance with ethical guidelines.

\subsection{Instrument}

The tool used to collect information in this study was an electronic questionnaire adopted and modified from King et al., (2009), where respondents were asked to answer questions surrounding three main themes in four parts. Since piloting the questionnaire helps the researcher to improve the clarity of the item wordings and the instructions (Dörnyei, 2007), the questionnaire was sent to six students who were similar to the target sample. After the piloting phase, the questionnaire was sent via WhatsApp application to several distance learning groups at the English Language Department at KAU.

\subsection{Questionnaire Design}

The questionnaire adopted from King et al. (2009) and modified by the researcher was based on the aim of the study and the context. Firstly, the survey began with a full description of the research, its aim, and how the data will be used. To protect the participants' privacy, a statement confirming their anonymity was added at the end of the first section. Secondly, biographical data questions about gender, type of learning, and the participants' perceptions of frequent cheating in distance learning followed. Thirdly, single-answer MCQs consisted of six questions with seven dichotomous questions (agree and disagree). Fourthly, an open-ended question was added. Finally, the questionnaire ended with a letter thanking participants for their participation in the study. The final version of the survey consisted of a total of 16 items, which were divided into three sub-sections:

1. Participants' views on the ways they used to cheat in distance learning.

2. Participants' perceptions toward the reasons for cheating in distance learning.

3. Participants' opinions about finding some solutions to the problem of cheating among distance learning students.

\section{Data Analysis \& Results}

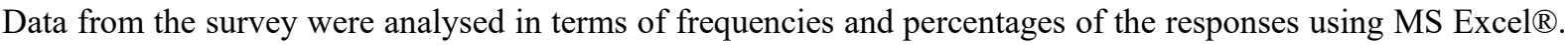
The open-ended question was analysed thematically and processed as one of the qualitative method types. Results were divided into three constructs as shown in Table 1 below:

Table 1. DL Students' Perceptions about Cheating in Distance Learning

\begin{tabular}{llll}
\hline Part (1) & Always & Sometimes & Rarely \\
$\begin{array}{l}\text { 1. In an ONLINE course, to what extent do you think that a } \\
\text { student may take the opportunity to "cheat" }\end{array}$ & $34.5 \%$ & $60 \%$ & $5.5 \%$ \\
& Yes & No & About the Same \\
$\begin{array}{l}\text { 2. Is cheating more frequent, in an online course than a regular } \\
\text { classroom? }\end{array}$ & $52.7 \%$ & $9.1 \%$ & $38.2 \%$
\end{tabular}

Table 1 shows that $60 \%(\mathrm{n}=34)$ of the participants answered that students sometimes tend to cheat in distance learning, while $52.7 \%(\mathrm{n}=30)$ considered cheating in distance learning programmes more frequent than in regular, traditional classrooms. 
Table 2. DL Students' Perceptions on Methods of Cheating

\begin{tabular}{llll}
\hline Part (2): Did you as a distance-student .... & Always & Almost & Never \\
\hline 3. $\quad$ open the course book during an online exam & $25.5 \%$ & $34.5 \%$ & $\mathbf{4 0 \%}$ \\
4. have another person do your exam. & $11 \%$ & $34.5 \%$ & $\mathbf{5 4 . 5 \%}$ \\
5. obtain the exam from another student who did the test before you. & $32.7 \%$ & $\mathbf{4 3 . 6 \%}$ & $24 \%$ \\
6. help other students during the exam & $34.5 \%$ & $\mathbf{4 5 . 5 \%}$ & $20 \%$ \\
7. use more time on an online exam when some technical problems & $12.7 \%$ & $27.3 \%$ & $\mathbf{6 0 \%}$ \\
happen for the extension of the exam. & $\mathbf{4 0 \%}$ & $36.4 \%$ & $23.6 \%$ \\
8. send the answers to other students & $35 \%$ & $22.2 \%$ & $\mathbf{4 2 . 8 \%}$ \\
9. have the ID of other students and answer their exam & $\mathbf{6 0 \%}$ & $23.7 \%$ & $16.3 \%$ \\
10. use Google to copy and paste the correct answers & &
\end{tabular}

Table 2 above highlights the responses of the participants regarding the various ways of cheating where $34.5 \%$ of the participants used the course book during an online exam, and $43.6 \%$ obtained the exam from another student, who took the test before them. In addition, $45.5 \%$ helped other classmates during the exam, while another $40 \%$ sent the correct answers to the WhatsApp group, and 60\% used Google to copy and paste the right answers on the test.

Table 3. DL Students' Perceptions about Reasons for Cheating

\begin{tabular}{llc}
\hline Part (3): Why do you -as a distance learning student- cheat? & Agree & Disagree \\
\hline 11. I cheat because I only want grades, not knowledge & $\mathbf{7 8 . 2 \%}$ & $21.8 \%$ \\
12. I cheat because of my frequent absence from the virtual classrooms, and the & $\mathbf{6 9 . 1 \%}$ & $30.9 \%$ \\
misunderstanding of content. & $\mathbf{6 3 . 6 \%}$ & $36.4 \%$ \\
13. I cheat due to the short time of tests & $18.2 \%$ & $\mathbf{8 1 . 8 \%}$ \\
14. I cheat because other classmates are cheating & $\mathbf{7 0 . 9 \%}$ & $29.1 \%$ \\
15. I cheat because of some technical problems
\end{tabular}

According to the data gathered from the participants in part III as shown in Table 3 above, $78.2 \%$ of students said they cheat because they want grades, not necessarily knowledge. Most of them (69.1\%) did not attend regularly, so they did not understand the course, while $63.6 \%$ said that they cheat due to the lack of time in the quizzes and exams, and $70.9 \%$ of participants blamed technical problems for their cheating behaviour.

In the qualitative data part of the questionnaire (open-ended question), students provided possible solutions to prevent cheating in distance learning. From the open-ended question responses, which was analysed thematically, students offered solutions that are threefold: (1) the main responsibility falls on the students themselves and possible solutions included increasing their sense of responsibility and conscience, having help from a tutor to aid understanding when something is misunderstood, and studying hard, (2) the teacher could employ some methods to prevent cheating, which includes shortening the course syllabus, creating different quizzes for each student, and making sure that all students access the test at the same time, and (3) they recommended that the university disable the copy and paste features from all platforms during exams and they also expressed their desire to see midterm tests held in regional testing centres and a larger number of students admitted in traditional programmes.

\subsection{Findings}

Analysis of the data indicated that most distance learning students cheat under the name of "helping others". Cheating is considered by some students as social networking, where they support each other and exchange correct answers or obtain the whole exam from another student who did it before them. The Internet and websites play an important role, where participants used Google's (search engine) during the exam and then copied and pasted answers from different websites. Although some students gave their exam to others, most of them did not do that. Moreover, some used an open book without the teacher's permission, while others used their friends' IDs to gain access to their tests and conducted these tests themselves on their behalf. These were the routine methods used by some students to cheat. 
Many reasons were offered to the problem of cheating from the students' perceptions. For example, they blamed teachers and the university itself claiming that due to the long course and short time of exams, students cheat. Additionally, because of the technical problems that occur most of the time, they feel they must cheat to get grades. Other reasons expressed by the students that were behind cheating included laziness, dishonesty (expressed by some participants as the absence of fearing God), easiness of cheating compared to studying, ample opportunities for cheating via apps or online websites, and the lack of self-confidence and time for actual studying. In addition, a lot of students wanted grades without necessarily understanding the topics where they did not care about lectures and thus, did not attend many of those lectures. As a result, they had difficulties with the content, which caused them to cheat. Based on the previous findings, it appears that modern distance learning students have rather lax attitudes towards ethical principles when taking exams.

Finally, participants in this study suggested some solutions to prevent cheating in distance learning, starting with increasing the awareness and fear of God as well as teaching an ethics course about academic integrity in distance learning might be a good idea. Regarding the possible practical solutions for teachers, they suggested contacting distance learning students to know their academic level at the beginning of the course and then create more essay and short answer type tests. In addition, the university could employ an aid to prevent technical problems and unauthorized access to exams.

\subsection{Discussion}

This study focused on the ways, causes, and solutions of cheating in distance learning programmes at KAU in Jeddah, Saudi Arabia from the students' perspectives. The results showed that the most common ways for cheating are identity impersonation and consulting other classmates during exams, which is in line with the results from Ravasco (2012). The Internet also plays a major role in aiding cheating because of the opportunities it provides distance learning students. For example, they can open many websites during exams, obtain others' work without permission or citations, and copy correct answers, which is supported in the study conducted by Watson and Sottile (2010). As to the causes of online cheating, students complained that there was no time to study as most of them were part-time students and workers or parents, which is aligned with the study of Hosny and Fatima (2014), who found that lots of students cheat because there was not enough time to study. Non-regular attendance of virtual classes resulted in a lack of understanding of course content, which in turn pushed students to try to cheat for high achievement as reflected in Diego (2017). Finally, concerning students identifying some solutions to prevent cheating in online courses, their answers were divided into three thematically based ideas. They suggested that they themselves study hard, review their lessons regularly, as reported by the study conducted by Diego (2017), who emphasized on and recognized the importance of academic honesty. It is very substantial for the students to recognize the importance of learning and working harder, which is supported by King et al. (2009). Another solution for the absence of lectures is listening to recorded lectures or find a more knowledgeable person to help them understand the content of the courses. Moreover, they suggested various behaviours and instructional strategies from teachers and administrators, also cited by King et al. (2009) as well as believing that it is within the university's duties to provide good technical support and high security measures regarding exams and online tests.

\section{Conclusion}

To conclude, this study has investigated the students' perceptions of cheating in distance learning at the English Language Department at KAU in Jeddah, Saudi Arabia. The results have indicated that many participants admitted that they cheated during their online courses. They thought that cheating was caused by the inattention of the students towards learning or by the technical problems of online platforms or programmes. This can be minimised by understanding the reasons for cheating and having a complete image of the students' struggles. Finally, students must be made aware of their educational, social, and religious responsibilities and keep in mind that learning is not just for school, but for life. For the pedagogical implementation for this study, more online workshops about academic honesty and ethics should be provided for distance learning students; and a short technical course including all the expected problems, and solutions should be given before the beginning of the online semester. Developing and enforcing the university's Code of Ethics and raising awareness of its importance as well as catching and punishing those who engage in academic dishonesty is strongly suggested to combat the problem.

\subsection{Recommendations for Further Research}

For further studies on cheating on distance learning platforms, researchers could compare students' cheating across different courses in distance learning at various universities in order to distinguish the most vulnerable courses susceptible to cheating and identify the reasons behind this. They could also compare actual cheating and 
the students' perception of dishonesty in online courses through observation. Moreover, conducting interviews with the participants and teachers could offer a deeper view of the reasons behind cheating and academic dishonesty online.

\section{References}

Alghamdi, E. A., Rajab, H., \& Rashid, S. (2016). Unmonitored students self-created WhatsApp groups in distance learning environments: A collaborative learning tool or cheating technique. International Journal of Research Studies in Educational Technology, 5(2), 71-82.

Alhareth, Y., \& Mcbride, N. (2014). E-Learning in Saudi Higher Education: A Literature Review. International Journal of Reviews in Computing, 13(1), 48-56. Retrieved from http://www.ijric.org/volumes/Vol13/6Vol13.pdf

Almazova, N., Khalyapina, L., \& Popova, N. (2016). International youth workshops as a way of preventing social conflicts in global developing world. Paper presented at the 3-rd International multidisciplinary scientific conference on social sciences and arts. SGEM 2016.

Al-Nuaim, H. A. (2012). The use of virtual classrooms in e-learning: A case study in King Abdulaziz University, Saudi Arabia. E-Learning Digital Media, 9(2), 211-222. https://doi.org/10.2304/elea.2012.9.2.211

Baran, L., \& Jonason, P. K. (2020). Academic dishonesty among university students: The roles of the psychopathy, motivation, and self-efficacy. PLOS ONE, 15(8), e0238141. https://doi.org/10.1371/journal.pone.0238141

Choy, L. T. (2014). The strengths and weaknesses of research methodology: Comparison and complimentary between qualitative and quantitative approaches. IOSR Journal of Humanities and Social Science, 19(4), 99-104. https://doi.org/10.9790/0837-194399104

Diego, L. A. B. (2017). Friends with Benefits: Causes and Effects of Learners' Cheating Practices during Examination. IAFOR Journal of Education, 5(2), 121-138. https://doi.org/10.22492/ije.5.2.06

Dörnyei, Z. (2007). Research methods in applied linguistics. Oxford University Press.

Golden, J., \& Kohlbeck, M. (2020). Addressing cheating when using test bank questions in online Classes. Journal of Accounting Education, 52, 100671. https://doi.org/10.1016/j.jaccedu.2020.100671

Harashchenko, L., Komarovska, O., Matviienko, O., Ovsiienko, L., Pet'ko, L., Shcholokova, O., \& Sokolova, O. (2019). Models of corporate education in the United States of America. Journal of Entrepreneurship Education, 22(3), 1-6.

Hosny, M., \& Fatima, S. (2014). Attitude of students towards cheating and plagiarism: University case study. Journal of Applied Sciences, 14(8), 748-757.

Hurd, S. (2000). Distance language learners and learner support: beliefs, difficulties and use of strategies. J Links Letters 7: Autonomy in language learning, 7, 61-80.

Ibrahim, D. Z., Silong, A. D., \& Samah, B. A. (2002). Readiness and attitude towards online learning among virtual students. Paper presented at the 15th Annual Conference of the Asian Association of Open Universities, Nueva Delhi, India.

King, C. G., Guyette Jr, R. W., \& Piotrowski, C. (2009). Online exams and cheating: An empirical analysis of business students' views. Journal of Educators Online, 6(1), n1. https://doi.org/10.9743/JEO.2009.1.5

Malik, N., Al Shaer, F., \& Arora, B. (2019). A Web-enhanced Course in Foundation Program at Bahrain Teachers College: A Case Study. KnE Social Sciences, 48-59. https://doi.org/10.18502/kss.v3i24.5167

Masaryk, R., Sokolová, L., \& Túnyiová, M. K. (2018). Academic Self-Concept and the Use of Tablet Technologies in Czech and Slovak Schools. Studia Psychologica, 60(3), 167-182. https://doi.org/10.21909/sp.2018.03.760

Michael, T. B., \& Williams, M. A. (2013). Student equity: Discouraging cheating in online courses. Administrative Issues Journal Education Practice and Research, 3(2), 6. https://doi.org/10.5929/2013.3.2.8

Moore, J. L., Dickson-Deane, C., \& Galyen, K. (2011). e-Learning, online learning, and distance learning environments: Are they the same? The Internet Higher Education, 14(2), 129-135. https://doi.org/10.1016/j.iheduc.2010.10.001

Nichols, M. (2003). A theory for eLearning. Journal of Educational Technology Society, 6(2), 1-10. 
Owen, R. S. (2016). Cheating in online courses for financial aid fraud in the US. Administrative Issues Journal: Connecting Education, Practice, Research and Practice in Technology Enhanced Learning, 6(2), 116-133.

Raines, D. A., Ricci, P., Brown, S. L., Eggenberger, T., Hindle, T., \& Schiff, M. (2011). Cheating in online courses: The student definition. Journal of Effective Teaching, 11(1), 80-89.

Ravasco, G. G. (2012). Technology-aided cheating in open and distance e-learning. Asian Journal of Distance Education, 10(2), 71-77.

Razek, N. (2014). Academic integrity: A Saudi student perspective. Academy of Educational Leadership Journal, $18(1)$.

Rowe, N. C. (2004). Cheating in online student assessment: Beyond plagiarism. Online Journal of Distance Learning Administration, 7(2).

Sadeghi, M. (2019). A shift from classroom to distance learning: Advantages and limitations. International Journal of Research in English Education, 4(1), 80-88. https://doi.org/10.29252/ijree.4.1.80

Sukamolson, S. (2007). Fundamentals of quantitative research.

Watson, G., \& Sottile, J. (2010). Cheating in the digital age: Do students cheat more in online courses? Online Journal of Distance Learning Administration, 13(1). Retrieved from https://www.westga.edu/ distance/ojdla/spring131/watson131.html

\section{Copyrights}

Copyright for this article is retained by the author(s), with first publication rights granted to the journal.

This is an open-access article distributed under the terms and conditions of the Creative Commons Attribution license (http://creativecommons.org/licenses/by/4.0/). 